\title{
DANÇA É POLÍTICA PARA A CULTURA CORPORAL
}

\author{
Marina Souza Lobo Guzzo \\ Universidade Federal de São Paulo, Campus Baixada Santista, São Paulo, São Paulo, Brasil. \\ Conrado Augusto Gandara Federici \\ Universidade Federal de São Paulo, Campus Baixada Santista, São Paulo, São Paulo, Brasil. \\ Odilon José Roble \\ Universidade Estadual de Campinas, São Paulo, São Paulo, Brasil. \\ Vinicius Demarchi Silva Terra \\ Universidade Federal de São Paulo, Campus Baixada Santista, São Paulo, São Paulo, Brasil.
}

\begin{abstract}
Resumo:Este ensaio pretende situar o leitor no contexto da dança como produção artística, como política do corpo, traçando uma narrativa histórica sobre o percurso da sua prática, desde o início de sua criação no quattrocento italiano para a noção atual de dança politizada feita a partir de um corpo com múltiplas referências e informações que se apresenta hoje na sociedade contemporânea, com efeitos e influências dos adventos tecnológicos de comunicação. O texto foi pensado como uma introdução para profissionais e estudantes de Educação Física, que têm pouco contato com a cena da dança contemporânea, gerando um descompasso entre profissionais que atuam numa área de importância para o fortalecimento do que chamamos de cultura corporal. A dança pode ser política para a cultura corporal a partir do movimento crítico que faz em relação à realidade, questionando ou propondo possibilidades de ação e transformação da maneira que existimos.
\end{abstract}

Palavras-chaves: dança, política, cultura corporal.

\section{Argumento}

É crescente na Educação Física propostas de intervenção pedagógica que utilizam a dança como principal eixo de ação e reflexão, entendida como conteúdo da cultura corporal. A dança pode e deve ser pensada como um dos conteúdos a ser trabalhado na Educação Física conforme proposta descrita pelo clássico livro da área, que já completou duas décadas de sua publicação, Metodologia do ensino de Educação Física, assinado por um Coletivo de Autores (Soares e. Al, 1992). A partir dessa definição, de que a dança, o ritmo, a expressividade corporal é algo a ser trabalhado pelo profissional de Educação Física, é comum encontrarmos no currículo e na formação dos profissionais da área a disciplina Dança, ou Ritmo e expressão. No entanto, pouca informação sobre a história da dança e de sua potência políticatransformadora para/com o corpo circula nos cursos e conteúdos de formação, nas pesquisas e nas práticas do profissional de Educação Física - embora muitas graduações em Dança no Brasil tenham surgido dentro de Faculdades de Educação Física. A maioria dos cursos trabalha conteúdos práticos, com foco em uma dança de reprodução, em ensinar "passos de dança". 
Comumente, encontramos profissionais que trabalham com a dança, que não assistem ou frequentam a produção da dança artística em teatros, vídeos ou mesmo na internet (com o acesso facilitado dos dias de hoje). Essa "ausência" contribui para uma lacuna entre a produção artística contemporânea, histórica e a dança que é oferecida na Educação Física. Isso gera um descompasso entre profissionais que atuam numa área de importância para o fortalecimento do que chamamos de cultura corporal.

O presente ensaio surgiu da prática de quatro docentes de faculdades de Educação Física brasileiras, que perguntaram ao seus alunos: qual é entendimento que temos de dança? Qual o papel da dança na Educação Física? Por que existe uma separação tão grande entre a dança produzida artisticamente a dança feita e pensada na Educação Física? Por que os alunos e profissionais da área não frequentam espetáculos de dança? Por que questões como autoria, criação e política não são abordadas em disciplinas que abordam a dança nesse contexto? Esse texto pretende de maneira breve situar o leitor no contexto da dança como produção artística, como política do corpo, traçando uma narrativa histórica linear sobre o percurso da sua prática, desde o início de sua criação no quattrocento italiano para a noção atual de dança politizada feita a partir de um corpo híbrido que se apresenta hoje na sociedade contemporânea, com efeitos e influências dos adventos tecnológicos de comunicação."

É importante ressaltar que esse olhar histórico acontece de um determinado ângulo, a partir do propósito de contribuir com possíveis diálogos entre a produção de dança contemporânea e sua relação com a Educação Física. A estrutura historiográfica pode apresentar certa linearidade, propositalmente desenhada a partir de acontecimentos e autores que alinhavam essa narrativa. Optamos pela narrativa linear, pensando nos estudantes de graduação em Educação Física que têm pouco acesso às publicações na área de dança, abrangendo um referencial teórico diverso, que pode servir de consulta para pesquisas mais aprofundadas.

\section{Dança-espetáculo}

A dança é reconhecida como uma atividade que já existia em sociedades primitivas, mas sua estruturação como campo sistematizado de conhecimento e espetáculo está situada principalmente a partir do século XVII, com o surgimento do balé clássico. Até a virada do século XIX para o século XX, o termo balé estava diretamente associado à dança espetacular, como sendo uma das únicas possibilidades de se ver e apreciar uma forma de sistematização ou espetacularização do corpo dançante, sem falar, obviamente, das danças tradicionais ou camponesas de cada país e região que eram apresentadas de maneira "livre" e profana nas ruas e festas populares. Aconteceu, portanto, uma construção nova de sentidos e significados a partir de um projeto de elitização da dança, que passou a ser concebida como um divertimento da aristocracia cortesã.

O balé, considerado um conceito, abrange elementos muito diferentes, que variam de um balleto dançado por Guglielmo Ebreu na Itália no quattrocentro a uma obra como La Sylphide, interpretada por Maria Taglioni no século XIX, assim como uma peça criada pelo American Ballet Theatre para um público dos dias de hoje (MONTEIRO, 1998).

Ainda segundo a mesma autora, o balé foi uma invenção do Renascimento italiano, conforme documentos datados do século XV. Anos mais tarde, foi levado à França e de lá espalhou-se pelo mundo ocidental nos séculos XVII e XVIII. É na Itália que se inicia a formação de uma sociedade cortesã, ainda não enrijecida pela etiqueta. A dança da corte faz emergir uma nova etapa para a apreciação: ela se torna erudita com passos e métricas 
específicas. O próprio termo balé refere-se a uma circulação de discursos e repertórios sobre a dança da época. Segundo Monteiro, encontra-se relacionado a Balletti, que seria o diminutivo de Ballo, utilizado na Itália renascentista para designar "danças executadas num salão de baile por uma elite cortesã" (MONTEIRO, 1998, op. cit. 170).

A dança e a prática corporal e discursiva transformou-se de maneira relacionada aos movimentos políticos da monarquia e da elite burguesa, profissionalizou-se entre os séculos XVI e XVII e afastou-se dos sentidos que ela possuía inicialmente para a população de maneira geral. Passou a existir um distanciamento das pessoas a partir da profissionalização da dança. Essa profissionalização fez surgir novos papéis: os mestres de dança, os bailarinos profissionais, regras e elevação do nível técnico.

Nos séculos seguintes, o que se viu foi um grande aprimoramento técnico. A técnica do balé clássico é baseada no virtuosismo dos passos e na harmonia e leveza dos corpos desenhados nas coreografias. A profissionalização exigiu uma nova forma de comunicação com o público em um duplo sentido: sobre a maneira como a dança era feita e sobre o que ela almejava tratar. Existiam os libretos, onde eram contados os modos de criação ensinados de maître para executor, e também, em algumas vezes, onde era contada a história ou o mito relacionado àquela dança. $\mathrm{O}$ espaço - a arquitetura renascentista - contribuía e influenciava nos movimentos que eram sempre amplos, leves, longilíneos e belos.

No século XVII, sob a influência de Luís XIV, a dança da corte tornou-se a dança real. Conhecido como Rei Sol, desde muito cedo tomou aulas de Balé, dançou em muitos espetáculos e criou a figura do primeiro bailarino: perpetuando no palco a estratificação social da época, traduzindo a noção de frontalidade também para os corpos que dançavam.

Luís XIV criou também uma Academia Real de Dança que formaria bailarinos profissionais, possibilitando que novas investigações e aprimoramentos fossem desenvolvidos na dança, que entraria, assim, no Século das Luzes também com uma discursividade "iluminada".

A criação de uma escola possibilitou que a profissionalização e a relação de mestre e discípulos fosse estabelecida. Segundo Pereira (1998), neste momento a dança debatia-se entre dois pólos: o do Maravilhoso, que trazia a ideia do divertissements ${ }^{33}$, com grandes dificuldades técnicas que agradavam ao público presente demonstrando as possibilidades e incríveis façanhas do corpo dançante, e, o pólo do verossímel, que se pergunta: mas o que isso quer dizer? O que isso pode dizer?

Existia, já aí,o início de uma preocupação em relação à sistematização daquele conhecimento que estava sendo produzido. Neste período surgiram os primeiros discursos sobre a dança: os mestres começam a produzir registros sobre as descobertas, os passos, a criação e as coreografias. Jean-Georges Noverre (1727-1810) foi um estudioso do Balé responsável por uma importante ruptura no discurso sobre a dança: a partir de uma crítica aos balés de sua época, ele propôs uma reforma na dança, para que esta fosse entendida e chamada de balés de ação. Com suas cartas sobre dança, elaborou um primeiro pensamento acerca daqueles corpos, daquela prática e das contradições cartesianas colocadas: técnica versus expressividade, endereçamento.

Para Noverre de acordo com a interpretação de Monteiro, 2006, o Balé de ação utilizase da expressão gestual, incorpora a pantomina e com isso torna-se capaz de criar a ilusão. A

\footnotetext{
33 Para Monteiro o divertissement cumpria, como arte cortesã, uma função social específica de entreter os
} nobres. Era feito por nobres, para os próprios nobres. 
dança assim compreendida por ele no século XVIII opõe-se ao mero mecanismo dos passos. Esta tensão expressava-se em seus escritos: "É uma dança que veicula significados, que emociona, ao contrário da dança mecânica, que se contenta em agradar os olhos, incapaz de estabelecer uma comunicação com o público (...)" (MONTEIRO, 2006, op. cit. p. 34).

Em uma de suas cartas, o autor questiona justamente a noção do endereçamento aqui levantada. Existe alguma dança que é incapaz de se comunicar? Como entender o que se comunica na dança sem seu programa? Será que existe um questionamento sobre o corpo expressivo, sobre a poética da cena, sobre a ação da transformação daquela arte?

Todo balé complicado e prolixo que não trace com nitidez e desenvoltura a ação que representa, cuja intriga só se adivinhe com o programa na mão; todo balé cujo enredo não se faça sentir, que não ofereça uma exposição, uma intriga, um desenlace, será somente, segundo minhas idéias, um simples divertimento de dança mais ou menos bem executados que me afetará mediocremente, já que não tem caráter algum, desprovido de toda e qualquer expressão (MONTEIRO, 2006, op. cit. p. 197).

A importância de olhar para o balé hoje é poder entender a influência histórica que ele trouxe para a forma de apresentação e de comunicação da dança como uma arte "espetacular" que se perpetua até hoje na dança contemporânea. Um palco, um programa, corpos que dançam: muita coisa mudou, mas algumas estruturas de organizações permanecem.

Os grandes teatros, os salões, uma pequena elite apreciadora: tudo isso perpetuou um modelo político de forma estética que refletiu em um trabalho corporal específico e sistematizado para um tipo de dança, por muitos anos, e que sustenta-se ainda, em muitos lugares.

O começo da quebra deste paradigma segundo grande parte da literatura pesquisada, aponta para o trabalho de François Delsarte (1811-1871). A dança é cada vez mais marcada por sua característica expressiva e pelos estudos das possibilidades do corpo para realizar a comunicação dessas expressões. Há uma crescente dedicação aos estudos do gesto, da voz e da emoção. E Delsarte é quem se dedica a sistematizar um catálogo que estabelece a conexão dos gestos com os estados emocionais correspondentes. "A intensidade do sentimento comanda a intensidade do gesto" (BOURCIER, 2006).

Com uma história pessoal marcada por sofrimentos e frustrações na carreira artística, Delsarte responsabilizou seus mestres pelo seu fracasso, pois foi submetido a métodos arbitrários de ensino, baseados em tradições cegas. Seus estudos partem do canto e da voz e, aos poucos, constatam que a cada emoção ou imagem cerebral corresponde um movimento, ou uma tentativa de movimento (BOURCIER, 2006).

Tal constatação torna-se uma peça-chave para a dança moderna: a intensidade do gesto é comandada pela intensidade da emoção. A diferença é grande em relação ao balé ou à dança acadêmica, que está fundamentalmente preocupada com a execução técnica perfeita, buscando o máximo de beleza, sem qualquer relação com o estado de quem executa o gesto.

As influências da teoria de Delsarte sobre a dança são muitas, como aponta Bourcier (2006): a) o corpo todo é mobilizado para a expressão, especialmente o torso, considerado "motor do gesto" pelos dançarinos modernos, b) dos movimentos de contração e relaxamento dos músculos é que resultam a expressão (tension-release, são palavras utilizadas pelo método de Martha Graham anos mais tarde), c) todos os sentimentos têm traduções corporais: a extensão do corpo está relacionada ao sentimento de auto-realização, ao dobrar o corpo, traduz-se um sentimento de anulação etc. Delsarte sempre ensinou oralmente e sua teoria foi 
sistematizada por seu discípulo Alfred Giraudet. Outro discípulo, Steele MacKay, abandonou a França no início da guerra, permaneceu nos Estados Unidos e lá desenvolveu e divulgou a teoria de Delsarte, extraindo o termo harmonic gymnastics para uma aplicação corporal de sua teoria que se difundiu rapidamente pelo país, influenciando historicamente a dança moderna americana e alemã (BOURCIER, 2006).

Também os estudos de Émile Jaques-Dalcroze (1865-1950) interessam a esse período de múltiplas vozes da história da dança e influenciaram especificamente a escola germânica de dança expressionista. Como músico e pedagogo, Dalcroze desenvolveu uma nova abordagem para o movimento: a rítmica. Para ele, o corpo é um ponto de passagem entre pensamento e música. A partir daí, desenvolveu uma série de exercícios corporais para educar seus alunos em sentido musical completo. Para Dalcroze a dança era um produto da música, que contém em si a "verdade" sobre o sentimento a ser executado pelo gesto do bailarino.

O gesto em si mesmo nada é, todo seu valor está no sentimento que o anima, e a dança mais rica em combinações técnicas e atitudes corporais nunca deixará de ser apenas um divertimento sem valor nem alcance, se seu objetivo não for pintar em movimentos as emoções humanas (BOURCIER, 2006: 292)

O método Jaques-Dalcroze foi um sucesso na Europa, especialmente na Alemanha, através de Mary Wigman. Seu mérito foi principalmente descobrir e sistematizar uma pedagogia do gesto $^{34}$.

\section{A preocupação expressiva}

Segundo Foster (1986), Isadora Duncan foi revolucionária quando colocou outras questões à dança: a subjetividade de cada bailarino, a expressão pessoal e a realização autêntica de vocabulários próprios, que também fariam parte dessa forma de arte e deveriam ser, dessa maneira, apresentados e trabalhados.

A ruptura da dançarina e coreógrafa, no século passado, é talvez uma das mais populares no entendimento da dança como espetáculo e deslocou o discurso e a forma de se fazer dança no ocidente.

Isadora propôs uma quebra à rigidez do balé clássico e favoreceu uma exploração "naturalista" em que o movimento seria próximo ao do natural, do cotidiano. Essa movimentação, porém, não libertava o corpo do dançarino do treinamento técnico e disciplinar. Era também pelo treino excessivo que o corpo "incorporava" o movimento a ponto de mostrá-lo como cotidiano ou "natural". Isadora apresentou-se com a coreografia solo La Marseille em 1916 com uma túnica grega, dançando músicas de grandes compositores do século XIX como Beethoven, Chopin, Wagner.

Seus movimentos eram simples, e demonstravam com transparência seu humor e espírito. Essa apresentação causou enorme sucesso, arrrancou lágrimas da plateia e contrastou

34 Para um estudo aprofundado sobre Dalcroze sugerimos a leitura do trabalho de José Rafael Madureira, Émile Jaques-Dalcroze: sobre a experiência poética da rítmica: uma exposição em 9 quadros inacabados. Tese de Doutorado, Faculdade de Educação - UNICAMP, 2008, que, com a Educação Física, pesquisa e pensa o corpo expressivo a partir da Rítmica. 
definitivamente com o que se vinha produzindo no balé do séculos passados (FOSTER, 1986).

Duncan não estava sozinha nessa ruptura: outros coreógrafos como Loie Fuller, Ted Sahwn, Ruth St. Denis e Rudolf Laban entre outros, começavam um trabalho de construção de uma nova forma de pensar e viver a dança. O vocabulário e o estilo desse momento respondiam à uma estética expressionista. Nos anos 20 e 30, o expressionismo foi aprofundado por uma segunda geração de bailarinos e coreógrafos principalmente na Alemanha com Mary Wigman (aluna de Laban) e Estados Unidos com Doris Humphrey e Martha Graham (alunas de St. Denis e Ted Shawn).

Nas primeiras décadas do século XX, Rudolf von Laban (Hungria - 1879, Inglaterra 1958) deu início a uma sistematização para uma linguagem apropriada ao movimento corporal, com aplicações teóricas, coreográficas, educativas e terapêuticas. Laban criou um grande tratado de discursos da dança, desenvolvendo métodos, exercícios e pensamentos sobre como funciona e se relaciona o corpo do bailarino.

Atualmente, a Análise de Movimento Laban ou Labanálise (internacionalmente abreviada como LMA- Laban Movement Analysis) é usada como forma de descrição e registro de movimento cênico ou cotidiano (em pesquisas de cunho artístico e/ou científico), técnica de treinamento corporal (teatro, dança, musical), técnica coreográfica, método de diagnóstico e tratamento em dança-terapia.

A Labanálise, uma linguagem de mapeamento corporal baseada em quatro categorias (Corpo-Expressividade-Forma-Espaço), foi organizada para desenvolver alterações e expansões das habilidades expressivas rumo ao "Domínio do Movimento" (LABAN, 1978). Por meio da Labanálise, é possível identificar, descrever e transformar as características pertinentes ao treinamento corporal para a cena e as tendências de movimento de cada bailarino/pessoa na sua relação com o que acontece a sua volta. Tratam-se de padrões valorizados por uma determinada estética, como os de movimentos preferencialmente fortes e rápidos, podendo ser expandidos para inúmeras variações.

Laban fez entrar uma noção importante para a construção da dança contemporânea: a noção de esforço (GIL, 2005). Para ele, o esforço "é definido como o impulso interior na origem de todo o movimento". Seria um espécie de "força vital" que encerra em si mesmo toda a forma que o movimento terá. É nele que estão contidas as qualidades de peso, tempo, fluência, espaço, que variadas de acordo com a quantidade e intensidade identificam a forma e o conteúdo do movimento dançado. A busca por um discurso individuallizado, do poder do corpo e do bailarino (com sua história, caracaterísticas e necessidades) passou a ser incluído no pensamento da dança. Laban instaurou uma metodologia para pensar a dança moderna e de sistematizar os discursos sobre sua forma de ensino ou criação. Entre seus trabalhos mais importantes estão Scriftanz (1926), Effort (1947) Modern Education Dance (1948) e The Mastery of Movement stage (1954).

\section{Judson Dance Theater}

Mais tarde, enquanto na Europa se desenvolviam os frutos do expressionismo e das escolas modernas, que incluíam os trabalhos de Laban, Mary Wigman e outros, nos Estados Unidos, um movimento importante trouxe novas rupturas para o discurso da e sobre a dança, ou seja, influenciou sua maneira de fazer e de se organizar no mundo como linguagem artística. 
Os protagonistas de tal movimento foram um grupo de jovens coreógrafos, músicos, pintores, entre outros que se reuniam semanalmente na Judson Memorial Church (uma congregação protestante liberal, em Washington Square South, Nova York) para discutir seus últimos trabalhos coreográficos. Todos os presentes deveriam assistir ao trabalho de cada um e em seguida comentá-lo. Essas reuniões eram abertas ao público, que era convidado a fazer observações de qualquer tipo: "sobre qualquer aspecto político, social ou estético envolvido...na forma de pintura ou poemas ou pôsteres ou ensaios ou sentenças ou esculturas ou um clipping de jornal, ou fotos (...)" (BANES, S., 1983, op. cit. p. 37.).

As apresentações do Judson Dance Theater eram organizadas com a plateia sentada em bancos de costas para o altar e nas laterais da igreja, de modo a criar mais espaço para a atuação do(s) artista(s) que se apresentava(m). Com essa iniciativa democratizava-se a dança, colocando os artistas no mesmo plano dos espectadores e bem próximos uns dos outros diferente do palco italiano.

Num documento-manifesto-iconoclasta de 1965, Yvonne Rainer, uma das coreógrafas participantes do movimento propõe:

não ao espetáculo, não ao virtuosismo, não às transformações e à mágica, e ao faz-de-conta, não ao glamour e à transcendência da imagem do astro, não ao heróico, não ao anti-heróico, não à imaginação tola, não ao envolvimento do artista ou do espectador, não à sedução do espectador pelo artifício do artista; não à excentricidade, não ao mover-se ou a ser movido (STUART, 1998. op. cit. p. 198).

Esse movimento é chamado de dança pós-moderna americana e sua prática crítica e engajada rompeu com os padrões anteriormente estabelecidos pela dança moderna, abrindo para a dança novas fronteiras de ação e criação.

\section{A desconstrução do espetáculo}

Dos anos 60 para frente, as rupturas da dança transformaram sua maneira de se relacionar com o espectador, com sua desconstrução técnica e suas escolhas temáticas. Fazer a diferença do que já estava estabelecido marca os períodos que seguiram o Judson Dance Theater, tanto na Europa, como na América. A dança modificou-se em sua estrutura estética, a exemplos dos trabalhos da alemã Pina Bausch com a dança-teatro, Merce Cunningham nos Estados Unidos, a new dance na Holanda, o butô no Japão. Uma grande ruptura aconteceu nas artes de maneira geral, com o crescimento da investigação das performances e dos happenings, que misturavam diversas linguagens, através da justaposição, chamada collage.

A performance se caracteriza como um terreno interdisciplinar que mescla a música, a dança, a poesia, o teatro de vanguarda. O interesse principal dos artistas é de formalizar o ritual. Nesta linha, surge o que foi denominado de Live Art, uma arte viva, que aproveita da presença física do corpo para construir ações cotidianas em cenas espontâneas e improvisadas.

É o movimento artístico que visa dessacralizar a arte tirando-a de sua função meramente estética e elitista. A idéia de resgatar a característica ritual da arte, deslocando-a de espaços mortos como museus, galerias e teatros, colocando-a em uma posição viva, modificadora. Esse movimento é dialético, pois, na medida em que de um lado se tira a arte da posição sacra e 
inatingível, vai se buscar de outro, a ritualização dos atos comuns à vida: dormir, comer, etc. (COHEN, 1987. op. cit. p. 16).

É o que Sally Banes (1999) chama de "corpo efervescente", um corpo aberto ao mundo, com limites permeáveis, com fronteiras misturadas a partir da presença e combinação de linguagens. A autora compara esse conceito à ideia de corpo grotesco de Bakhtin (1999), pois ele é "virado de dentro para fora" (BANES, 1983. op. cit. p. 257). A ideia de um corpo polido pelas regras de conduta é esquecida, há uma ênfase na comida, na digestão, na excreção e na procriação, sempre acentuando as partes "baixas" do corpo, principalmente o sexo e a excreção. Esse corpo efervescente e grotesco imprime uma visão histórica, ritualística e coletiva, contra um corpo singular, psicologizado, privado e fechado do mundo moderno e pós-moderno. Segundo Banes (1999) na década de 1960 e 1970, as pessoas consideravam o corpo invulnerável e imortal, e desejavam ingerir, injetar e incorporar qualquer coisa nos seus corpos como drogas, dietas e até cirurgias plásticas. Os performers revelavam isso na cena, nas obras vivas que passavam por seus corpos e exploravam limites de manipulação, de dor, de resistência. Interessava problematizar o corpo em relação às questões sociais, culturais e políticas que aconteciam no mundo.

\section{Dança é política?}

Após os anos 70, com a transformação conceitual da cultura no mundo ocidental, a dança também foi contaminada tendo sido uma das principais consequências o entendimento e a ideia da "dança de autor" (Louppe, 2000). Isso significa que cada intérprete, criador, coreógrafo começa a transformar seu treinamento corporal, sua técnica para construir seu próprio caminho autoral na dança.

A preocupação da comunicação do corpo em movimento não está somente no gesto. Ela se desloca para o conteúdo do que esse movimento pretende expressar. Por conta disso, técnicas alternativas para trabalhar o corpo são incorporadas por esses grupos. Práticas orientais como yoga, kung-fu, artes marciais, e outras ocidentais como Pilates, Alexander, BMC são re-apropriadas e transformam-se em base para a construção do corpo que vai dançar. O Balé Clássico deixa então de ser a única técnica organizada e codificada que representa um padrão para criação na arte do movimento. Essa transformação dos padrões e da formação corporal da dança contemporânea influenciou uma mudança estética e política na forma como as coreografias eram apresentadas.

Um conjunto de princípios estéticos e filosóficos elegiam um "grande criador", que antes era o ponto gerador para uma obra coreográfica, ou um corpo dançante, a partir da historiografia de grandes mestres da dança moderna (Mary Wigman, Cunningham, Graham, etc). Havia uma coerência na construção de um corpo-dança, construída pela técnica pertinente para sua ação.

Laurence Louppe (2000), questiona sobre esta diferença entre um mestre de dança e as produções contemporâneas. No primeiro caso, a permanência de um padrão corporal, com imagens e técnicas construídas ao longo da história, onde o público identifica e reconhece códigos de movimentação, são construídas a partir da idéia do espetáculo. Existe uma referência corporal constitutiva. Já no segundo, a formação do bailarino é construída por diversas correntes, uma espécie de mestiçagem de técnicas e misturas de fontes culturais que atuam segundo a autora, apenas na superfície da obra artística. A mistura pode ser ilusória se o corpo do bailarino não for tocado. 
A ideia de hibridização do corpo opõe-se à de mestiçagem, por não evocar a ideia de universalidade cultural e globalizadora, ou pertencimento à grupos identitários. $\mathrm{O}$ híbrido é originário de engendramentos de pessoas, objetos, materialidades mistas, "não modificados em sua estrutura, mas enriquecidos pela acumulação de diferentes heranças genéticas ou culturais" (HARAWAY,1991), acontecendo por combinações, muitas vezes, únicas e acidentais.

A apropriação política da dança pelos dançarinos é o que, segundo Isabelle Ginot \& Marcelle Michel (2002), caracteriza a dança contemporânea hoje. Ou seja, uma atitude situada a partir de seu próprio ponto de vista da realidade, com um engajamento crítico nas maneiras de fazer dança, são características presentes nessa forma de arte. Esta postura instiga a busca por movimentos, formas, performances e apresentações que alterem e reflitam maneiras de entender o mundo.

A dança pode ser política para a cultura corporal a partir do movimento crítico que faz em relação à realidade, questionando ou propondo possibilidades de ação e transformação da maneira pela qual existimos. A dança como forma de comunicação e discurso, e principalmente como arte, tem o papel de testemunhar e co-construir os sentidos da vida no presente. Ela é entendida, ao mesmo tempo, como uma forma e um espaço de reflexão sobre as condições e necessidades coletivas, mesmo quando ela não se propõe a isso de maneira específica. Por ser uma manifestação artística complexa, ela possui uma rede de materialidades e sociabilidades que a sustentam e a cada espetáculo constrói-se uma maneira coletiva de narrar, posicionar-se, recortar a realidade.

Por conta disso, acreditamos que é importante que o profissional da Educação Física esteja atento à sua manifestação na contemporaniedade, entendendo sua história, incluindo referências, ritmos e gestualidades brasileiras, contribuindo para fruição e apreciação da dança como linguagem artística também para a área da Educação Física.

\section{DANCE AS POLITICS FOR THE BODY CULTURE}

Abstract:This article aims to situate the reader in the context of dance as an artistic product, a policy body, tracing a historical narrative about the course of his practice since the beginning of its creation in the italian quattrocento to the current notion of dance made from politicized a multiple body that presents itself today in contemporary society, with effects and influences of the advent of communication technology. The text is intended as an introduction for professionals and students of Physical Education, who have little contact with the contemporary dance scene, creating a gap between professionals working in an area of importance for the strengthening of the body we call culture. Dance can be a political body for culture from the movement that is critical in terms of reality, questioning or offering possibilities for action and change the way we exist.

Key-words: dance, politics, body culture.

\section{LA DANZA ES POLITICA PARA LA CULTURA CORPORAL}

Resumen:Este ensaio pretende situar al lector en el contexto de la danza como un producto artístico, un órgano normativo, la búsqueda de una narrativa histórica sobre el curso de su práctica desde el comienzo de su creación, en el Quattrocento italiano a la noción actual de la danza a partir de politización un cuerpo multiplo que se presenta hoy en la sociedad contemporánea, con los efectos e influencias de la llegada de la tecnología de la comunicación. El texto pretende ser una introducción para profesionales y estudiantes de Educación Física, que tienen poco contacto con la danza contemporánea, creando una brecha entre los profesionales que trabajan en un área de importancia 
para el fortalecimiento del cuerpo que llamamos cultura. La danza puede ser un órgano político de la cultura del movimiento que es crítica en términos de la realidad, el cuestionamiento o la oferta de posibilidades de acción y cambiar la forma en que existimos.

Palabras clave: danza, política, cultura corporal.

\section{Referências}

BANES, S. Democracy's Body: the Judson Dance Theater 1962-1964. Ann Arbor: UMI Research Press, 1983.

. Writing Dancing in the Age of Postmodernism. Hanover \& London: Wesleyan University Press, 1999.

BOURCIER, P. História da dança no ocidente. São Paulo: Martins Fontes, 2006.

COHEN, R. Performance como linguagem. São Paulo: Perspectiva, 1987.

FOSTER, S. Reading Dancing. Bodies and subjects in contemporary American Dance. Berkley: University of California Press, 1986.

GIL, J. Movimento total, o corpo e a dança. São Paulo: Iluminuras, 2005.

GINOT, I. \& MICHEL M. La danse au XXe siècle. Paris: Larousses/Veuf, 2002.

HARAWAY, D. A Cyborg Manifesto: Science, Technology, and Socialist-Feminism in the Late Twentieth Century. In: Simians, Cyborgs and Women: The Reinvention of Nature. New York; Routledge, 1991, pp.149-181.

LABAN, R. Domínio do Movimento. São Paulo: Summus Editorial, 1978.

LIMA, D. Corpo, política e discurso na dança de Lia Rodrigues. Rio de Janeiro: UniverCidade Editora, 2007.

LOUPPE, L. Poétique de la danse contemporaine. Bruxelles: Contradanse, 1997.

Corpos Híbridos. In: Lições de dança 2. Rio de Janeiro: UniverCidade, 2000. Publicado originalmente na Revista Art Press, número 209 em versão francês/inglês. Traduzido por Gustavo Ciríaco.

Poétique de la danse contemporaine. La suite. Bruxelles: Contredanse, 2007.

MADUREIRA, J. R. O Ritmo, a Música e a Educação [DALCROZE, Émile Jaques, 1965]. IN: Revista Pro-Posições Vol.18 n.1 (52) - jan./abr, 2007.

MONTEIRO, M. Noverre. Cartas sobre dança. São Paulo: Edusp-FAPESP, 2006.

verCidade, 1998. Balé, tradição e ruptura. In: Lições de Dança 1. Rio de Janeiro: Uni- 
PEREIRA, R. Gruas Vaidosas. In: Lições de dança 1. Rio de Janeiro: UniverCidade, 1999.

SOARES, C. Et al. Metodologia do ensino da Educação Física. São Paulo: Cortez, 1992.

STUART, I. A experiência do Judson Dance Theater. In: Lições de Dança - Volume 1. Rio de Janeiro: UniverCidade, 1998.

Recebido em: 12/01/2014

Revisado em: 21/07/2014

Aprovado em: 09/09/2014

Endereço para correspondência:

marinaguzzo2@gmail.com

Marina Souza Lobo Guzzo

Universidade Federal de São Paulo, Campus Baixada Santista.

Av. Alm. Saldanha da Gama, 89

Ponta da Praia

11030-400 - Santos, SP - Brasil 